\title{
Fracture Resistance of Incisal Fragments Following Reattachment With Different Techniques in Simulated Crown Fractures
}

\author{
Fatih Tulumbacı ${ }^{1 *}$, Volkan Arıkan², Aylin Akbay OBA², Serdar Bağlar ${ }^{3}$ \\ ${ }^{1}$ Ankara Yıldırm Beyazıt University of Dentistry, Department of Pediatric Dentistry, Ankara, Turkey \\ ${ }^{2}$ Kırıkkale University Faculty of Dentistry, Department of Pediatric Dentistry, Kırıkkale, Turkey \\ ${ }^{3}$ Kırıkkale University Faculty of Dentistry, Restorative Dentistry, Kırıkkale, Turkey
}

\author{
*Correspondence to \\ Fatih Tulumbacl, \\ Ankara Yıldırm Beyazıt University \\ of Dentistry, Department of \\ Pediatric Dentistry, Ankara, Turkey. \\ Tel: 03123241555 ; \\ Fax: 03123241505 \\ Email: fatihtulumbaci@hotmail.com
}

Published online 27 September 2017

\begin{abstract}
Introduction: The aim of the present study was to evaluate and compare the effect of acidetching and $\mathrm{Er}$, Cr:YSGG laser treatment before the reattachment of incisal fragments in coronal fractures of permanent incisor teeth.

Methods: Sixty-six sound human maxillary incisors were randomly divided into 3 groups $(n=22)$. Teeth were embedded in self-cure acrylic resins by leaving one-third of the crowns out, and uncomplicated crown fractures were obtained using an Instron testing device. The fragments were reattached using 3 different procedures and a hybrid resin composite (Z250): Group I: Acid etching + Prime \& Bond NT; Group II: Er,Cr:YSGG + Prime \& Bond NT; Group III: Er,Cr:YSGG + Acid etching + Prime \& Bond NT. The percentages of shear bond strengths were determined by comparing fracture strengths of sound and reattached teeth for 3 groups. All data were analyzed statistically with Kruskal-Wallis $\mathrm{H}$ test.

Results: Mean fracture strengths of the reattached fragments were between $51.02 \%$ and $62.93 \%$ of that of the sound teeth in all groups. Group I had significantly higher percentages of shear bond strength values $(P<0.05)$ when compared to group II and group III. No significant difference $(P>0.05)$ was found between group II and group III.

Conclusion: The findings of the present study show that Er,Cr:YSGG laser irradiation prior to the reattachment of incisal fragments has a negative effect on fracture strength.

Keywords: Er,Cr:YSGG laser; Dental trauma; Reattachment.
\end{abstract}

\section{Introduction}

Anterior crown fractures are the most common form of dental injuries that affects mainly children and adolescents. ${ }^{1}$ They affect around $25 \%$ of the population under the age of 18 and of these, $96 \%$ involve maxillary incisors ( $80 \%$ central incisors and $16 \%$ lateral incisors). ${ }^{2}$ Traumatic injuries usually cause uncomplicated crown fractures, involving enamel and dentin only and without pulp exposure. ${ }^{3}$ The management of these cases is of utmost importance since these injuries do not only damage dental tissues, but also create a negative psychological impact on children and their parents. ${ }^{4}$ Thus, restoration of a fractured crown is important both esthetically and functionally.

A variety of treatment modalities have been tried for crown fractures including stainless steel crowns, orthodontic bands, pin retained resin, basket crowns, composite resins with acid-etch adhesive, porcelain veneers and jacket crowns. ${ }^{5}$ Despite recent developments in adhesive materials and restorative techniques, there is no restorative material that can reproduce the esthetic and function of the natural dental structures. ${ }^{6}$ Although full ceramic crowns and laminate veneers provide satisfactory results with their good esthetic properties and color stabilities, these treatment approaches are very destructive in the restoration of fractured anterior teeth. ${ }^{7}$ Compared with other restorative techniques, reattachment of fractured fragments, which offers improved esthetics and function, is the most conservative treatment approach. Therefore, the reattachment technique should be considered particularly in children, as it helps to preserve dental tissues during tooth development. ${ }^{8,9}$ However, the resistance of the reattached teeth to traumatic forces is lower, and is reported to be about $50 \%-60 \%$ of intact teeth. ${ }^{1}$ The primary causes of failure of the reattached tooth fragment are usually a new trauma or excessive masticatory forces. ${ }^{10}$

Several materials and methods have been used by

Please cite this article as follows: Tulumbacı F, Arıkan V, OBA AA, Bağlar S. Fracture resistance of incisal fragments following reattachment with different techniques in simulated crown fractures. J Lasers Med Sci. 2017;8(4):181-185. doi:10.15171/jlms.2017.33. 
clinicians in an attempt to improve the fracture strength of the rebonded fragment. ${ }^{8,11,12}$ Dental restorative materials are connected to dental surfaces via chemical adhesion and micromechanical retention. ${ }^{13}$ Traditionally, etching the enamel surface with orthophosphoric acid, a concept first proposed by Buonocore, has been commonly used to increase the bond strength between the composite and enamel. ${ }^{14}$ This method also removes the smear layer after preparation. $^{15}$

Erbium, chromium: yttrium, scandium, gallium, garnet (Er,Cr:YSGG) is a laser with a wavelength of $2780 \mathrm{~nm}$ and it is reported to be effective on hard tissue and cavity preparation on teeth. It was reported that when the laser is used along with a water air spray, no or little $\left(2^{\circ} \mathrm{C}\right)$ increase in temperature occurs in dental pulp. ${ }^{16,17}$ The dentin surface treated by laser appears clean, without a smear layer and with the tubules open and clear. ${ }^{18}$ One of the intended uses reported for Er, Cr: YSGG, is the etching of enamel surface, as an alternative to acid etching, before applying resins. ${ }^{19}$

To date, there are no published studies investigating the effect of Er,Cr;YSGG laser when used for etching prior to the reattachment of crown fragments. Therefore, the purpose of the present study was to compare the shear bond strength (SBS) of composite resin to enamel surface using conventional acid etching and laser etching.

\section{Methods}

A total of 90 human sound permanent maxillary incisors extracted for periodontal reasons were collected. Teeth were collected after signature of informed consent form by patients. The extracted teeth were kept in $5 \%$ sodium hypochlorite solution for 1 hour and remaining periodontal tissues were removed with a scaler. The cleaned teeth were stored in saline solution until experimental procedures. ${ }^{20}$

For the simulation of crown fractures, the teeth were embedded in self-cure acrylic resin by leaving one third of the crowns out. Each specimen was then placed in an Instron testing device (Lloyd; Fareham, Hants, England), in such a manner that the angle between the vestibular surface of the tooth and horizontal plane was 180 degrees. The load was applied to vestibular enamel surface by means of a reinforced knife-edge stainless-steel at a crosshead speed of $10 \mathrm{~mm} / \mathrm{min}$ (Figure 1). The force required to fracture each tooth was recorded in kilogram force. Since uncomplicated fractures were included in the

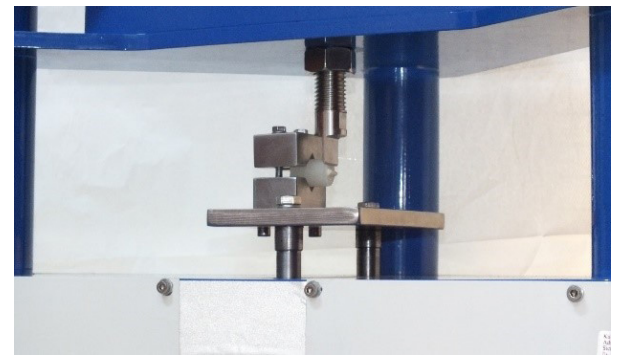

Figure 1. Fracturing the Teeth in the Instron Device.

study, 24 of the 90 teeth were excluded during fracture procedures and study continued with 66 teeth. The specimens were stored in $0.9 \%$ saline solution until the restoration procedures were performed. ${ }^{8}$

\section{Reattachment Procedures}

The teeth were randomly divided into 3 groups $(n=22)$. The fragments were reattached using one of 3 different methods, with a total-etch bonding agent (Prime \& Bond NT) and a hybrid resin composite (Filtek Z250) (Table 1): Group I: Acid etching + Prime \& Bond NT;

Group II: Er,Cr:YSGG + Prime \& Bond NT;

Group III: Er,Cr:YSGG + Acid etching + Prime \& Bond NT.

In group I, 37\% phosphoric acid (Tetric N Ceram, Ivoclar Vivadent) was applied along the fractured margins of the tooth and the fragment for 15 seconds. The etched surfaces were then rinsed off thoroughly with water and gently air dried. Bonding agent (Prime and Bond NanoTechnology) was applied with the help of an applicator tip to the etched surfaces of the fragment and the tooth. Two consecutive coats were applied; gently air thinned and then light cured for 10 seconds. Resin composite material was then applied on the fracture surface of the tooth and on the fragment according to manufacturer's instructions. The fragment was then approximated along the fractured tooth margin, excess materials on the tooth surface were removed and light cured for 40 seconds each on labial and lingual surface.

In group II, the fragment and the tooth surface were etched using Er,Cr:YSGG laser with these settings, 20 $\mathrm{Hz}, 5 \mathrm{~W}, 90 \%$ air and $80 \%$ water. Then the laser-etched surfaces were gently air dried and bonding agent (Prime and Bond Nano-Technology) was applied with the help of an applicator tip to the laser etched surfaces of the

Table 1. Materials Used in the Present Study

\begin{tabular}{lll}
\hline Material & Manufacturer & Composition \\
\hline Prime \& Bond NT & DENTSPLY/DeTrey Konstanz, Germany & Di- and trimethacrylate resins, PENTA, Nanofillers \\
& & - Amorphous silicon dioxide, Photoinitiators, \\
Z250 Resin composite & SM ESPE, St. Paul, MN, USA & bis-GMA, UDMA, Bis-EMA \\
Phosphoric acid & Tetric N Ceram, Ivoclar Vivadent & $37 \%$ phosphoric acid \\
\hline
\end{tabular}


fragment and the tooth. The rest of the procedures were similar to the first group.

In group III, the fragment and the tooth surface were etched using Er,Cr:YSGG laser with these settings, 20 $\mathrm{Hz}, 5 \mathrm{~W}, 90 \%$ air and $80 \%$ water. Then the laser-etched surfaces were gently air dried and $37 \%$ phosphoric acid was applied. The rest of the procedures were similar to the other 2 groups (Figure 2).

\section{Thermal Cycling and Debonding Procedures}

All restored specimens were kept in distilled water at $37^{\circ} \mathrm{C}$ for 24 hours, and subsequently subjected to thermal cycling ( 1000 cycles; $5-55 \pm 2{ }^{\circ} \mathrm{C}$; dwell time $=15$ seconds; transfer time $=10$ seconds) ${ }^{21,22}$ The specimens were, then, loaded at $10 \mathrm{~mm} / \mathrm{min}$ at the same point used for fracturing the intact teeth. The force required to fracture the reattached fragment was recorded in kilogram force. The percentages of SBSs were determined by comparing fracture strengths of sound and reattached teeth for 3 groups..$^{23,24}$

\section{Statistical Analysis}

The statistical analysis was performed with SPSS 11.0 (SPSS Inc., Chicago, IL, USA) program. SBS percentages of the groups were compared with Kruskal-Wallis $\mathrm{H}$ test Bonferroni correction. The level of significance for the test was set to 0.05 .

\section{Results}

The percentages of fracture strengths after reattachment compared to sound teeth in 3 experimental groups are shown in Table 2. The percentages were between $51.02 \%$ and $62.93 \%$ of that of the sound teeth in all groups. Group I had the highest fracture strength after reattachment (between $45.18 \%$ and $75.11 \%$ of the sound teeth). Group III showed the lowest percentages of fracture strengths after reattachment (Table 2). According to the statistical analysis, the percentages in group I were significantly higher compared to both group II and group III $(P<0.05)$. The difference between group II and group III was not statistically significant $(P>0.05)$.

\section{Discussion}

In this study, only maxillary incisors were included because these teeth are most prone to trauma. Sound and restored teeth were subjected to a shear force in accordance with

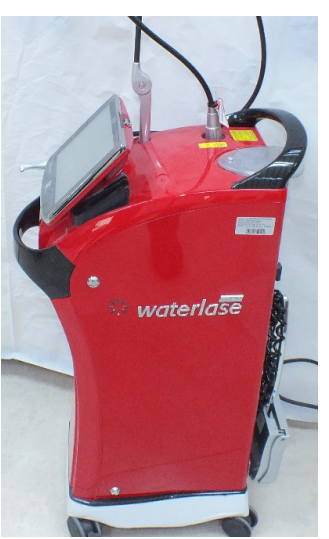

Figure 2. Er, Cr:YSGG Waterlase Laser Device.

the experimental protocol as described by Reis et al. ${ }^{23}$ This protocol allows for measuring the fracture strength of each tooth when intact and after reattachment. ${ }^{1,11,23}$ When the surface anatomy of a fractured crown is examined, the surface runs parallel to the main direction of enamel prisms, whereas the orientation of a sectioned surface is perpendicularly aligned to the diamond saw used to section the incisal edge. ${ }^{23}$ The fracturing protocol used in the study ensures smear-free fractured surfaces, whereas the sectioning technique produces a cut surface of coronal dentin that incorporates a smear layer. As well known, the bond strength to uncut (smear-free) dentin is reported to be lower than that obtained with smear-covered, sectioned coronal dentin..$^{25}$ Since the fracture line is not regular and no smear layer exists in real crown fractures, simulation of crown fractures with this technique is more realistic. Restorations of tooth fragments is still primarily dependent on strong and durable enamel bonding. ${ }^{9}$ Selfetching bonding agents are the most widely used adhesive systems and are used in combination with phosphoric acid to provide stronger adhesion to enamel. ${ }^{11}$ Several in vitro studies have clearly indicated that phosphoric acid etching increases the bond strength to enamel. ${ }^{26,27}$ Therefore, Prime \& Bond NT, which is an etch-and-rinse adhesive system was preferred in our study.

Self-etching adhesives provide adequate dentin bond strengths without acid etching, however the use of these materials is not recommended on enamel without etching procedure. ${ }^{27,28}$ It prevents good penetration of the bonding resin on enamel due to higher microleakage and shallow

Table 2. Mean Fracture Resistance of Reattached Teeth in 3 Experimental Groups

\begin{tabular}{lccccccccc}
\hline & \multicolumn{4}{c}{ Group } & \multicolumn{3}{c}{ Kruskal-Wallis H Test } \\
\cline { 2 - 7 } & N & Mean & Median & Min & Max & SD & Rank.Avg. & H & P \\
\hline Group 1 & 22 & 62.93 & 65.35 & 45.18 & 75.11 & 9.52 & 46.95 & \\
Group 2 & 22 & 53.30 & 54.07 & 44.15 & 68.71 & 6.89 & 29.18 & 16.936 & 0.000 \\
Group 3 & 22 & 51.02 & 52.97 & 39.12 & 61.32 & 6.32 & 24.36 & $1-2$ \\
Total & 66 & 55.75 & 54.62 & 39.12 & 75.11 & 9.20 & & $1-3$ \\
\hline
\end{tabular}


etching patterns. ${ }^{29}$ Laser etching is an alternative to acid etching on enamel and dentine. Laser etching applications does not produce vibration or heat, is painless and used routinely. ${ }^{13}$ The dentin surface treated by laser etching appears clean, without a smear layer and with the dentin tubules open. ${ }^{18}$ During laser etching, anfractuous enamel and dentine surface crates are formed, which are caused by microexplosions resulting from the sudden boiling of water within the tissue. ${ }^{13}$ Although there are studies comparing bonding strength of surfaces that were acid and laser etched, ${ }^{19,30}$ the samples used in the present study had no smear layer on fracture surfaces, therefore, mimicked real fractures.

The mean re-attachment strength percentages found in our study (50\%-60\%) corroborate with the values reported by Reis et al. $^{23}$ According to the results of the present study, the highest fracture strength recovery was obtained in Acid etching + Prime \& Bond NT group (62\%, 93\%). Laser etched samples showed significantly lower fracture strengths $(P<0.05)$. These findings indicate that the bond strength decreases following acid etching. These results are in line with previous studies. ${ }^{31,32}$ Beer et al compared bond strength between acid - laser etching on dentin. The bond strength on dentin was significantly higher in acid etched group compared to the laser-etched group. ${ }^{31}$ Jaberi Ansari et al compared the SBSs of composite attached to enamel and dentine surfaces prepared by acid etching or Er,Cr:YSGG laser etching. The bonding strengths in the acid etched group were significantly higher than all other laser-etched groups. Er,Cr:YSGG laser + acid etched group showed a higher mean SBS compared to the laser etching only group but no statistically significant difference was observed between the 2 groups. ${ }^{32}$ The authors stated that the use of laser combined with acid etching results in the same bond strength as the acidonly etched teeth. They also reported that laser etching resulted in more heterogeneous surfaces compared to the surfaces obtained with acid etching. Acid etching typically produced a repeating surface pattern. On the other hand, laser etching produced extensive surface fissuring, less regular and non-uniform surface patterns. ${ }^{13}$

Irradiation of dentin with an Er,Cr:YSGG laser creates a rough surface with chimney-like formations due to the preferential removal of intertubular dentin. ${ }^{33}$ Phosphoric acid etching following Er,Cr: YSGG laser etching results in partly loss of the advantages of this ideal surface morphology. Acid application dissolves the intertubular dentin too, thus destroying the chimneylike formations and widening the orifices of the dentinal tubules. ${ }^{31}$ Furthermore, consecutive acid etching causes demineralization zones with unpredictable depths ${ }^{34}$ and insufficient diffusion depth of resin monomers. ${ }^{35}$ The lower bonding strength values observed in the laseretched groups in the present study can probably be a result of this effect.

\section{Conclusion}

This study demonstrated that, for the reattachment of simulated crown fracture fragments, the conventional acid etching results in significantly higher mean SBSs compared to laser etching. Studies investigating the effect of different Er,Cr:YSGG laser etching parameters may further enlighten the subject.

\section{Ethical Considerations}

Not applicable.

\section{Conflict of Interests}

None.

\section{References}

1. Reis A, Loguercio AD, Kraul A, Matson E. Reattachment of fractured teeth: a review of literature regarding techniques and materials. Oper Dent. 2004;29(2):226-233.

2. Ozel E, Cildir A, Ozel Y. Re-attachment of anterior tooth fragment using a self-etching adhesive: a case report. $J$ Contemp Dent Pract. 2008;9(1):77-83.

3. Pamir T, Eden E, Sebahtin Ahmed S. Shear bond strength of restorations applied to un-complicated crown fractures: an in vitro study. Dent Traumatol. 2012;28(2):153-157. doi:10.1111/j.1600-9657.2011.01063.x

4. Belcheva A. Reattachment of fractured permanent incisors in schoolchildren (review). Journal of IMAB. 2008;14(2):97100. doi: 10.5272/jimab.14-2-2008.97.

5. Sengun A, Ozer F, Unlu N, Ozturk B. Shear bond strengths of tooth fragments reattached or restored.J Oral Rehabil. 2003;30(1):82-86.

6. Vijayaprabha K, Marwah N, Dutta S. A biological approach to crown fracture: Fracture reattachment: A report of two cases. Contemp Clin Dent. 2012;3(Suppl 2):S194-S198. doi:10.4103/0976-237x.101091.

7. Koutayas SO, Vagkopoulou T, Pelekanos S, Koidis P, Strub JR. Zirconia in dentistry: part 2. Evidence-based clinical breakthrough. Eur J Esthet Dent. 2009;4(4):348-380.

8. Pusman E, Cehreli ZC, Altay N, Unver B, Saracbasi O, Ozgun G. Fracture resistance of tooth fragment reattachment: effects of different preparation techniques and adhesive materials. Dent Traumatol. 2010;26(1):9-15. doi:10.1111/j.1600-9657.2009.00855.x.

9. Macedo GV, Diaz PI, De OFCA, Ritter AV. Reattachment of anterior teeth fragments: a conservative approach. $J$ Esthet Restor Dent. 2008;20(1):5-18. doi:10.1111/j.17088240.2008.00142.x.

10. Andreasen JO, Andreasen FM, Andersson L. Textbook and Color Atlas of Traumatic Injuries to the Teeth. John Wiley \& Sons; 2013.

11. Pagliarini A, Rubini R, Rea M, Campese M. Crown fractures: effectiveness of current enamel-dentin adhesives in reattachment of fractured fragments. Quintessence Int. 2000;31(2):133-136.

12. Lo Giudice G, Lipari F, Lizio A, Cervino G, Cicciu M. Tooth fragment reattachment technique on a pluri traumatized tooth. J Conserv Dent. 2012;15(1):80-83. doi:10.4103/09720707.92613 .

13. Martinez-Insua A, Da Silva Dominguez L, Rivera FG, 
Santana-Penin UA. Differences in bonding to acidetched or Er:YAG-laser-treated enamel and dentin surfaces. J Prosthet Dent. 2000;84(3):280-288. doi:10.1067/ mpr.2000.108600.

14. Salama FS. Effect of laser pretreated enamel and dentin of primary teeth on microleakage of different restorative materials. J Clin Pediatr Dent. 1998;22(4):285-291.

15. Attrill DC, Farrar SR, King TA, Dickinson MR, Davies RM, Blinkhorn AS. Er:YAG $(\lambda=2.94 \mu \mathrm{m})$ Laser Etching of Dental Enamel as an Alternative to Acid Etching. Lasers Med Sci. 2000;15(3):154-161. doi:10.1007/pl00011311.

16. Secilmis A, Altintas S, Usumez A, Berk G. Evaluation of mineral content of dentin prepared by erbium, chromium:yttrium scandium gallium garnet laser. Lasers Med Sci. 2008;23(4):421-425. doi:10.1007/s10103-0070498-y.

17. Hibst R. Lasers for Caries Removal and Cavity Preparation: State of the Art and Future Directions. J Oral Laser Applications. 2002;2(4): 203-212.

18. Takeda FH, Harashima T, Kimura Y, Matsumoto K. Comparative study about the removal of smear layer by three types of laser devices. J Clin Laser Med Surg. 1998;16(2):117-122. doi:10.1089/clm.1998.16.117.

19. Lin S, Caputo AA, Eversole LR, Rizoiu I. Topographical characteristics and shear bond strength of tooth surfaces cut with a laser-powered hydrokinetic system. J Prosthet Dent. 1999;82(4):451-455.

20. Singhal R, Pathak A. Comparison of the fracture resistance of reattached incisor tooth fragments using 4 different materials. J Indian Soc Pedod Prev Dent. 2012;30(4):310316. doi:10.4103/0970-4388.108927.

21. Mitsui FH, Peris AR, Cavalcanti AN, Marchi GM, Pimenta LA. Influence of thermal and mechanical load cycling on microtensile bond strengths of total and selfetching adhesive systems. Oper Dent. 2006;31(2):240-247. doi:10.2341/05-20.

22. Cehreli SB, Gungor HC, Karabulut E. Er,Cr:YSGG laser pretreatment of primary teeth for bonded fissure sealant application: a quantitative microleakage study. $J$ Adhes Dent. 2006;8(6):381-386.

23. Reis A, Kraul A, Francci C, et al. Re-attachment of anterior fractured teeth: fracture strength using different materials. Oper Dent. 2002;27(6):621-627.

24. Simonsen RJ. Traumatic fracture restoration: an alternative use of the acid etch technique. Quintessence Int Dent Dig. 1979;10(2):15-22.

25. Kijsamanmith K, Timpawat S, Harnirattisai C, Messer HH. Micro-tensile bond strengths of bonding agents to pulpal floor dentine. Int Endod J. 2002;35(10):833-839.

26. Van Landuyt KL, Kanumilli P, De Munck J, Peumans M, Lambrechts P, Van Meerbeek B. Bond strength of a mild self-etch adhesive with and without prior acid-etching. $J$ Dent. 2006;34(1):77-85. doi:10.1016/j.jdent.2005.04.001.

27. Erhardt MC, Cavalcante LM, Pimenta LA. Influence of phosphoric acid pretreatment on self-etching bond strengths. J Esthet Restor Dent. 2004;16(1):33-40; discussion 41.

28. Torii Y, Itou K, Nishitani Y, Ishikawa K, Suzuki K. Effect of phosphoric acid etching prior to self-etching primer application on adhesion of resin composite to enamel and dentin. Am J Dent. 2002;15(5):305-308.

29. Kanemura N, Sano H, Tagami J. Tensile bond strength to and SEM evaluation of ground and intact enamel surfaces. J Dent. 1999;27(7):523-530.

30. Takada M, Shinkai K, Kato C, Suzuki M. Bond strength of composite resin to enamel and dentin prepared with Er,Cr:YSGG laser. Dent Mater J. 2015;34(6):863-871. doi:10.4012/dmj.2015-053.

31. Beer F, Buchmair A, Korpert W, Marvastian L, Wernisch J, Moritz A. Morphology of resin-dentin interfaces after Er,Cr:YSGG laser and acid etching preparation and application of different bonding systems. Lasers Med Sci. 2012;27(4):835-841. doi:10.1007/s10103-011-0979-x.

32. Jaberi Ansari Z, Fekrazad R, Feizi S, Younessian F, Kalhori KA, Gutknecht N. The effect of an Er,Cr:YSGG laser on the micro-shear bond strength of composite to the enamel and dentin of human permanent teeth. Lasers Med Sci. 2012;27(4):761-765. doi:10.1007/s10103-011-0961-7.

33. Van Meerbeek B, De Munck J, Mattar D, Van Landuyt K, Lambrechts P. Microtensile bond strengths of an etch\&rinse and self-etch adhesive to enamel and dentin as a function of surface treatment. Oper Dent. 2003;28(5):647-660.

34. Matos AB, Palma RG, Saraceni CH, Matson E. Effects of acid etching on dentin surface: SEM morphological study. Braz Dent J. 1997;8(1):35-41.

35. Carvalho RM, Ciucchi B, Sano H, Yoshiyama M, Pashley DH. Resin diffusion through demineralized dentin matrix. Rev Odontol Univ São Paulo. 1999;13(4):417-424. 